\title{
Sobre el comercio exterior mexicano y el TLCAN
}

\section{Osvaldo Bardomiano M.* :}

Mucho se ha debatido en la comunidad académica y entre el público en general acerca de los impactos del Tratado de Libre Comercio de América del Norte (tLCAN) que suscribieron Canadá, Estados Unidos (eU) y México, en particular ahora que cumplió 20 años. Con la entrada en vigor en 1994 es relativamente claro el impacto que tuvo en México dado el comportamiento de las exportaciones e importaciones, ya que antes de la firma del Tratado las exportaciones tuvieron una fase descendente y posterior a la firma tuvieron un salto significativo.
Hoy las exportaciones e importaciones mexicanas siguen con una tendencia básicamente ascendente (véase Gráfica 1).

No obstante lo anterior vale la pena reexaminar algunos datos importantes de México y del conjunto de los socios comerciales teniendo en cuenta que a un tratado de libre comercio como lo es el TLCAN se le debe pedir básicamente la promoción y el acceso creciente de las exportaciones mutuas, y el establecimiento de las condiciones que permitan atraer inversión extranjera. Esto precisamente

\section{Gráfica I}

México: exportaciones e importaciones, 1990-2013
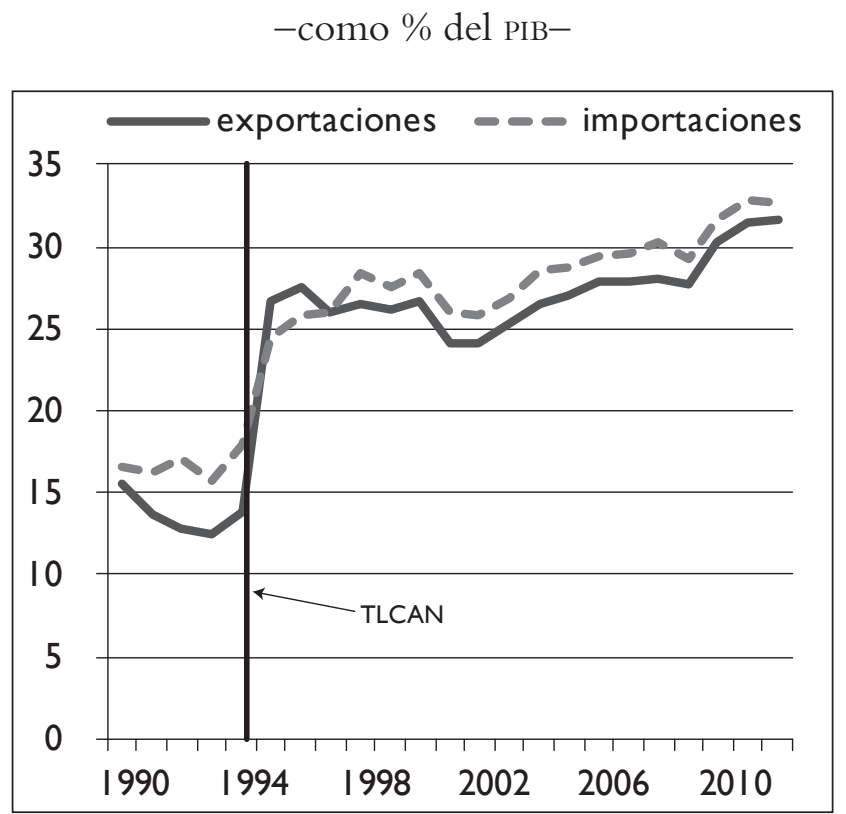

Fuente: elaboración propia con datos del BID, 2014.

* El autor es integrante del Seminario de Credibilidad Macroeconómica, FE-UNAM y agradece los comentarios de Gabriel Delgado Toral. Las ideas aquí expresadas son responsabilidad del autor. 
Economía Informa núm. 386 mayo - junio • 2014 - " " "

conforma la siguiente nota: en primer término se revisa el comercio exterior de México en torno al TLCAN, $y$ el intercambio de los tres socios comerciales en segundo lugar, finalmente se ofrece algún comentario a manera de conclusión.

\section{Comercio mexicano en torno al TLCAN}

Una mirada de largo plazo al comercio exterior permite observar dos grandes ámbitos: uno estaría representado por los coeficientes más básicos del comercio exterior y el otro por el comportamiento de las exportacio- nes e importaciones manufactureras. Analicemos, en 1993 el coeficiente de apertura para la economía mexicana era de apenas $27.5 \%$, lo que muestra la poca interacción con el resto del mundo hasta entonces; con la entrada en vigor del TLCAN y su libre flujo de bienes y servicios dentro de la región el coeficiente al cierre de ese año representó el 30.7\% y en 1996 de 52\%. Estos datos nos permiten ver la transición hacia una economía con relaciones más intensas hacia el exterior.

El libre intercambio permitió que el comercio exterior mexicano aumentara: mientras en 1993 las exportaciones alcanzaron 51700 millones

\section{Gráfica 2}

México: balanza comercial (BC), cuenta corriente (CC) y coeficiente de apertura $\left(\mathrm{CA}^{1}\right), 1990-2013$

-como \% del PIB-

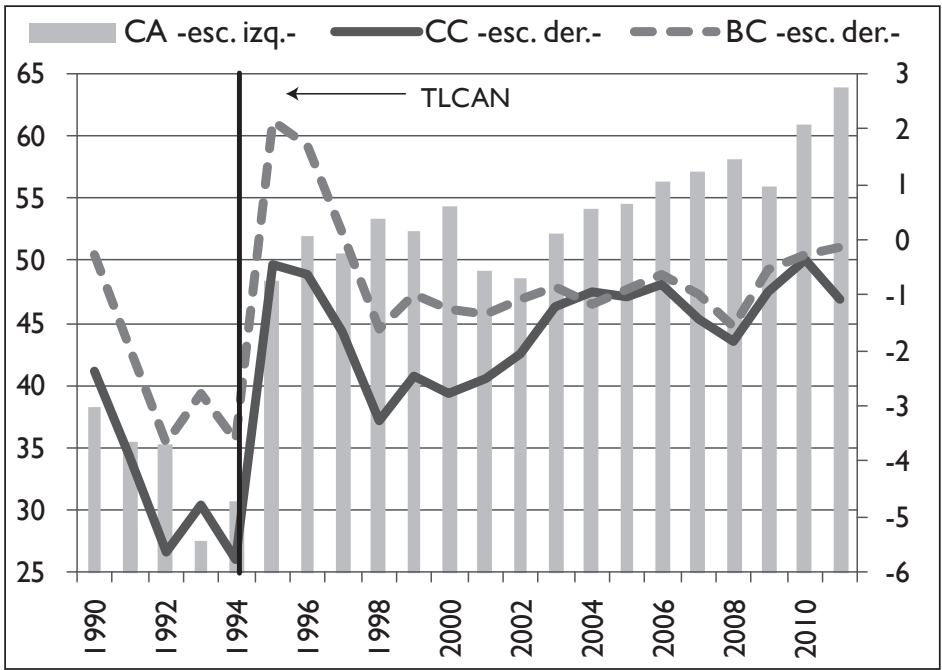

1/ Medido como el cociente de exportaciones más importaciones sobre el PIB. Fuente: elaboración propia con datos del BID, 2014. 
de dólares, para 2012 fueron de 358 mil millones de dólares, y a su vez, las importaciones 57600 millones de dólares y 360 mil millones de dólares, respectivamente. Si observamos el comportamiento de la balanza comercial y el saldo de cuenta corriente vemos que ambas variables antes de la fecha de corte tenían una tendencia claramente a la baja, es decir, fuertes déficits; en 1994 tocaron el punto mínimo para repuntar en 1995 y para el caso de la balanza comercial incluso se logró alcanzar un superávit (véase Gráfica 2).

Antes de la apertura comercial México se caracterizaba por una ser una economía exportadora, mayoritariamente, de materias primas, petróleo y minerales lo que no alentaba una promoción industrial y manufacturera competitiva. Con la firma del Tratado la composición de las exportaciones fue cambiando; en 1990 el coeficiente de exportación manufacturera, por ejemplo, representaba $63 \%, 10$ años después $83.5 \%$ y en $201275.19 \%$ como porcentaje del total de las exportaciones del país. En lo que respecta a importaciones manufactureras en 2012 fue de 80.5\% respecto del total.

El estudio más reciente para México de la Organización Mundial del Comercio(омc), 2014, referente a las políticas comerciales señala que la mayor parte de la producción del sector manufacturero que incluye las plantas maquiladoras se destina a la exportación donde $80 \%$ de ese total se dirige hacia EU. La producción nacional avanza hacia la generación de mayor valor agregado en sectores como el automotriz, el aeroespacial o el electrónico, sin descartar que se necesita ir a un paso más acelerado en esta materia.

\section{Intercambios comerciales de América del Norte}

Con los datos más recientes de la OMC, actualizados hasta el año 2012, se revisará en el presente apartado la dinámica e interacción comercial que tienen los tres socios del TLCAN, así como también la relación que tienen con países pertenecientes a otras regiones del mundo o a otro bloque económico. El análisis se centrará en dos grandes rubros: primero por el grupo de bienes que exportan e importan y segundo por el destino y origen de esos bienes.

En cuanto al primer punto, las principales exportaciones consisten en bienes manufactureros, México exporta 72.7\%, Estados Unidos $71.3 \%$ y Canadá $46.3 \%$, en los tres casos son respecto del total de sus exportaciones. En combustibles y productos mineros y productos agrícolas Canadá es el principal exportador mientras México y EU ocupan el segundo y tercer lugar, respectivamente. En lo que respecta a importaciones, México y 
Canadá mantienen un déficit en bienes manufactureros, mientras Estados Unidos exporta más de lo que importa, es decir, mantiene un superávit.

En importaciones de combustibles y productos mineros eu es el principal consumidor, los otros dos socios para el año de estudio tuvieron un superávit. En productos agrícolas Canadá es el principal importador, México importa $7.3 \%$ de este tipo de bienes y lo hace en mayor medida respecto de sus exportaciones. Estados Unidos importa $6.1 \%$ de productos agrícolas, siendo el de menor de los tres socios comerciales, pero valorando el tamaño de su mercado interno es bien conocido que es uno de los principales consumidores a nivel mundial (véase cuadro 1).

Lo anterior nos permite valorar un panorama general de la dinámica que mantienen los socios del TLCAN en el comercio internacional por tipo de bienes. Ahora analizaremos el comercio por origen y destino con la finalidad de ver la relación que mantienen los tres socios comerciales de América del Norte internamente y la interacción que tienen con otros países y regiones económicas. Como lo muestran los datos el principal socio comercial de México es Estados Unidos, ya sea por el lado de las exportaciones o por de las importaciones.

Las exportaciones mexicanas tienen como tercer destino Canadá y la relación que mantiene con este país en lo que respecta a las importaciones no figura entre los cinco socios principales. El socio comercial de mayor importancia de Canadá es Estados Unidos a donde se dirigen esencialmente sus exportaciones y de donde proviene en primer lugar sus im-

\section{Cuadro I}

TLCAN: comercio por tipo de bienes, 2012

-como porcentaje del total respectivo-

\begin{tabular}{|l|l|c|c|c|}
\hline & \multicolumn{1}{|c|}{ Productos } & México & Estados Unidos & Canadá \\
\hline \multirow{2}{*}{ exportaciones } & productos agrícolas & 6.2 & 11.1 & 13.8 \\
\hline & combustibles y productos mineros & 17.8 & 12.1 & 32.7 \\
\cline { 2 - 5 } & manufacturas & 72.7 & 71.3 & 46.3 \\
\hline \multirow{2}{*}{ importaciones } & productos agrícolas & 7.3 & 6.1 & 8.2 \\
\hline & combustibles y productos mineros & 11.6 & 20.8 & 14.0 \\
\hline & manufacturas & 78.2 & 69.3 & 73.6 \\
\hline
\end{tabular}

Fuente: elaboración propia con datos de la omc, 2014. 
portaciones. Por lo menos en el año de estudio México representó, para Canadá, $1.2 \%$ de sus exportaciones y $5.5 \%$ de sus importaciones, lo que nos permite visualizar que la relación entre ambas naciones no es de las más estrechas desde la perspectiva comercial de Canadá (véase cuadro 2).

Ahora veamos la dinámica que mantienen los miembros del TLCAN con otros países y regiones: la Unión Europea (UE) es el principal socio comercial de los tres países integrantes del tratado; China y Japón en el continente asiático, también tienen una fuerte presencia; Brasil y Corea tienen exclusiva relevancia en el comercio con México. Entonces, para América del Norte, en general, Centroamérica y Sudamérica tienen un peso ínfimo en la balanza comercial, al igual que los países de medio oriente, África y Rusia (que por sí solo es un amplio mercado).

Uno de los principales socios de Eu es la UE, que por cierto mantiene un superávit con esa región, sin embargo con China tiene un déficit de donde provienen en primer lugar sus importaciones, este país asiático supera a México y a Canadá como origen de las importaciones de EU. Japón no deja de ser significativa su presencia en Eu que por cierto también logra mantener un superávit en el año 2012. China y la UE en Canadá también son de sus principales socios ya sea por el lado de sus exportaciones como de sus importaciones. Con todo este panorama podemos ver que el TLCAN es una zona dinámica al interior y con otras regiones.

\section{Cuadro 2 \\ TLCAN: comercio por origen y destino, 2012}

\begin{tabular}{|c|c|c|c|c|c|c|c|c|c|c|c|}
\hline \multicolumn{4}{|c|}{ Panel A } & \multicolumn{4}{|c|}{ Panel B } & \multicolumn{4}{|c|}{ Panel C } \\
\hline \multicolumn{4}{|c|}{ México } & \multicolumn{4}{|c|}{ Estados Unidos } & \multicolumn{4}{|c|}{ Canadá } \\
\hline \multicolumn{2}{|c|}{ exportaciones } & \multicolumn{2}{|c|}{ importaciones } & \multicolumn{2}{|c|}{ exportaciones } & \multicolumn{2}{|c|}{ importaciones } & \multicolumn{2}{|c|}{ exportaciones } & \multicolumn{2}{|c|}{ importaciones } \\
\hline $\begin{array}{l}\text { Estados } \\
\text { Unidos }\end{array}$ & 77.8 & $\begin{array}{l}\text { Estados } \\
\text { Unidos }\end{array}$ & 50.1 & Canadá & 18.9 & China & 19.0 & $\begin{array}{l}\text { Estados } \\
\text { Unidos }\end{array}$ & 74.5 & $\begin{array}{l}\text { Estados } \\
\text { Unidos }\end{array}$ & 50.6 \\
\hline $\mathrm{UE}^{1}$ & 5.9 & China & 15.4 & $\mathrm{UE}^{1}$ & 17.2 & UE & 16.7 & $\mathrm{UE}^{1}$ & 8.5 & China & 11.0 \\
\hline Canadá & 2.9 & UE & 11.0 & México & 14.0 & Canadá & 14.0 & China & 4.3 & UE & 10.9 \\
\hline China & 1.5 & Japón & 4.8 & China & 7.2 & México & 12.0 & Japón & 2.3 & México & 5.5 \\
\hline Brasil & 1.5 & Corea & 3.6 & Japón & 4.5 & Japón & 6.4 & México & 1.2 & Japón & 3.3 \\
\hline
\end{tabular}

1/ Unión Europea (UE) incluye 27 países.

Fuente: elaboración propia con datos de la OMC, 2014. 


\section{Conclusión}

La apertura comercial debe de ir acompañada de otro tipo de políticas que permitan competir con las demás economías que generan bienes y servicios de mayor valor agregado, de alta tecnología e innovación y es de suma relevancia distinguir los alcances reales y posibles de la apertura comercial, no se le puede pedir que resuelva todo ni tachar como el causante de otros problemas que son responsabilidad exclusiva de otras áreas. Un tratado comercial no delega otras responsabilidades que tiene cada país por mejorar, por ejemplo, la calidad del empleo, la productividad o llevar a cabo una agenda de reformas. En los términos plantea- dos para la evaluación del TLCAN observamos que ha sido una experiencia acertada en algunos sectores de la economía mexicana. No es tiempo de que las economías se cierren sino que se habrán a los mercados mundiales.

\section{Referencias}

Banco Interamericano de Desarrollo (2014), The Latin American and Caribbean Macro Watch Data Tool, Washington, abril.

Organización Mundial del Comercio (омс) (2014), Estadísticas del Comercio Internacional, Ginebra, abril.

Secretaría de Economía (2014), Dirección general de inversión extrajera, México, abril. 